\title{
DESENVOLVIMENTO INDUSTRIAL E MERCADO DE TRABALHO NO RIO GRANDE DO SUL: $1920-1950^{1}$
}

\author{
Ronaldo Herrlein Jr. \\ Fundação de Economia e Estatística
}

\begin{abstract}
RESUMO
Este artigo aborda o desenvolvimento da indústria regional sul-rio-grandense e de seu mercado de trabalho no periodo compreendido entre 1920 e 1950. Nosso objetivo é considerar em que medida as condições observadas nessa indústria, que em 1920 pagava salários e operava com produtividade superiores à da indústria paulista, viram-se alteradas nas três décadas seguintes. Conclui-se que, embora o padrão de desenvolvimento industrial regional tenha se preservado em largos traços, o acréscimo de produtividade foi insuficiente para manter os elevados niveis relativos de salários, que também se viram prejudicados pela ampliação da oferta de trabalho.
\end{abstract}

PALAVRAS-CHAVE: economia do Rio Grande do Sul; desenvolvimento industrial; mercado de trabalho industrial; desenvolvimento regional comparado.

\section{INTRODUÇÃO}

Abordamos neste artigo o desenvolvimento da indústria regional sul-rio-grandense e de seu mercado de trabalho no período compreendido entre 1920 e 1950. Nosso objetivo é considerar em que medida as condições observadas nessa indústria, que em 1920 pagava salários e operava com produtividade superiores aos da indústria paulista, viram-se alteradas nas três décadas seguintes. Partindo da apresentação de uma síntese sobre as origens e a configuração do padrão de desenvolvimento industrial regional observado na Primeira República (seções 2 e 3), faremos uma primeira abordagem das estatísticas dos censos industriais de 1940 e 1950, em confronto com algumas variáveis demográficas (seção 4), procurando formular hipóteses preliminares para uma explicação das

\footnotetext{
1 Este texto é uma versão preliminar de um capítulo da tese de doutoramento do autor, em elaboração junto ao Instituto de Economia da UNICAMP, sob orientação do Professor João Manuel Cardoso de Mello. O autor agradece os comentários da economista Vera Regina F. Carvalho (UNIVATES) a um primeiro rascunho desse trabalho. $\mathrm{O}$ texto foi originalmente elaborado como uma versão para o debate nas Segundas Jornadas Uruguayas de Historia Económica (julho/1999, Montevideo) e no IIIo Congresso Brasileiro de História Econômica (ago.-set./1999, Curitiba).
}

permanências e transformações que experimentaram o padrão regional de desenvolvimento industrial e o mercado de trabalho da indústria gaúcha (seção 5).

O período em foco é de especial interesse, pois corresponde a uma etapa prévia à integração do mercado interno para a produção industrial (TARGA, RIBEIRO \& HERRLEIN JR., 1998), durante a qual a industrialização brasileira esteve restringida pela quase completa ausência de um departamento produtor de bens de produção (TAVARES, 1998). A precariedade do sistema nacional de transportes de cargas (BARAT, 1969) e o relativo isolamento geográfico estadual permitiram à indústria sul-rio-grandense atender ao seu mercado regional em condições de proteção frente à concorrência da indústria paulista, que experimentava acelerada expansão ${ }^{2}$.

\footnotetext{
2 A perspectiva de investigação desse trabalho está baseada na seguinte hipótese geral, fundadora da linha de pesquisa "Estudos Regionais Comparados" do Núcleo de Estudos de História Econômica, Social e Política (NEHESP-FEE): "devido à configuração geoeconômica do Brasil durante o século XIX e ao tipo de inserção da economia brasileira na divisão internacional do trabalho, a transição do escravismo para o capitalismo deu lugar ao desenvolvimento de (pelo menos) dois tipos diversos de acumulação de capital durante a primeira metade do século XX - um na região cafeicultora e outro no Rio Grande do Sul” (TARGA, 1988: 148).
} 


\section{ORIGENS DA INDÚSTRIA E DO MERCA- DO DE TRABALHO}

A indústria sul-rio-grandense surgiu no último quartel do século XIX, quando a implantação de algumas fábricas metalúrgicas e têxteis combinouse à evolução fabril de muitas manufaturas, nas quais se investiram frações importantes de capitais comerciais acumulados (LAGEMANN, 1980) $)^{3}$. De um modo geral, o fator decisivo para a constituição das firmas industriais foi o aporte de capital comercial. Sobretudo o capital acumulado nos fluxos mercantis que integravam a zona colonial e sua produção agrícola e agroindustrial à cidade de Porto Alegre. Através dessa, a produção da zona colonial alcançava o porto de Rio Grande e, desde esse porto, às demais regiões e ao exterior. Embora apenas em alguns poucos casos o artesanato comercial tenha dado origem à indústria com base em acumulação própria, essa atividade artesanal, exercida em ampla escala nas comunidades surgidas a partir das colônias de imigrantes europeus e descendentes, forneceu mão-de-obra especializada que favoreceu a formação de indústrias. Em alguns setores, como o de carnes e têxteis, houve aporte de capitais externos, fosse em escala individual, fosse como resultado de decisões de inversão de grandes companhias estrangeiras. As ações econômicas do Estado (administração estadual), no sentido de estimular as exportações regionais para os demais estados da federação, mediante a redução de impostos e a encampação de ferrovias e portos (ALMEIDA, 1992), contribuíram para alavancar a expansão comercial e o surgimento de indústrias.

Essa indústria regional seria gestada ao longo de toda a Primeira República, assumindo perfis diferenciados nas principais cidades do estado, nas duas primeiras décadas do século XX (SINGER, 1977, p. 175). Em Porto Alegre e nas maiores cidades da zona colonial, havia uma diversificada indústria de bens de consumo não-durável, originada principalmente a partir da acumulação comercial, com predominância de pequenos e médios estabelecimentos, voltados ao atendimento do mercado regional de bens de consumo não-

3 Concomitantemente, ocorria a difícil conversão das charqueadas para o trabalho assalariado. Ver a respeito Targa (1996c). duráveis (alimentação, bebidas, têxtil, vestuário, calçados, vidros e metalúrgica). Nas cidades da zona sul do estado, Rio Grande e Pelotas, havia um contingente menor de estabelecimentos em poucos ramos industriais (têxtil, alimentação, fumo e couros) e com uma maior concentração da estrutura da produção, na qual sobressaíam estabelecimentos médios e grandes. Nessas cidades, devido às vantagens de localização junto ao único porto marítimo e por constituírem juntas o principal pólo de acumulação comercial e urbanização da zona de produção pecuária extensiva e das charqueadas, surgiram "empresas que nasceram grandes" (SOUZA, 1973, p. 80), cuja produção desde logo se destinava majoritariamente a ser "exportada" para os mercados regionais brasileiros.

Tomando-se o conjunto da indústria regional ao final dos anos 1910, os estabelecimentos voltados para a "exportação" eram minoria, situando-se nos ramos têxtil e nos de processamento de carnes e de fumo. "Em regra a indústria nasceu voltada para o atendimento dos mercados locais, suplementando as importações [...] [e suas atividades] buscavam cobrir as amplas necessidades de seus consumidores através de uma produção diversificada" (LAGEMANN, 1980, p. 116).

Nesta fase de surgimento e expansão da produção industrial nacional a que corresponde a Primeira República, essa produção destinava-se a mercados regionais cujas dimensões e grau de integração dependiam, via de regra, do dinamismo das exportações de produtos agrícolas ao mercado mundial ${ }^{4}$. Paul Singer identifica duas "estratégias de industrialização" possíveis num país de desenvolvimento retardatário, ambas marcadas por um caráter substitutivo, de importações ou de produção artesanal preexistente (1984, p. 214). A substituição de importações voltava-se para o mercado urbano já inserido na economia capitalista, cuja expansão dependeu "do dinamismo do SME [setor de mercado externo], ou seja, do crescimento da produção para o mercado mundial”.

\footnotetext{
4 Convém desde logo assinalar que "a peculiaridade da economia das colônias européias no Sul do Brasil é que ela não se liga ao mercado mundial por meio de um dos poucos produtos 'coloniais', mas sim ao mercado interno, ao qual fornece gêneros alimentícios e matérias-primas” (SINGER, 1977, p. 169; sem negrito no original). Essa condição favorecia essa economia, pois implicava diversidade dos mercados a atender, seja em termos de produtos, seja quanto às regiões.
} 
Por sua vez, a substituição da produção artesanal pela fabril "implicava a unificação dos mercados locais e sua integração [sic] na divisão nacional de trabalho" (1984, p. 214). Mas também a unificação desses mercados, que se fazia em escala regional, dependia do dinamismo do SME de cada área.

Embora possamos presumir que os dois caminhos de surgimento da indústria ocorreram nas diversas regiões, as condições do Rio Grande do Sul foram particularmente propícias para a formação das atividades manufatureiras artesanais, tanto de caráter doméstico quanto de caráter comercial, e posteriormente para o surgimento da indústria através de pequenos e médios estabelecimentos capitalistas que passaram a dispor do conjunto do mercado regional, reorganizando ramos manufatureiros preexistentes ${ }^{5}$. A integração do mercado regional do Rio Grande do Sul, viabilizada ao longo da Primeira República pela navegação fluvial e pela rede ferroviária, resultou do dinamismo que essa economia logrou obter através das "exportações" de sua produção agropecuária, principalmente (mas não exclusivamente) aos mercados da região cafeeira. Era dessa forma que a economia regional articulava-se em uma divisão nacional do trabalho, enquanto produtora agropecuária e agroindustrial que tinha nos demais mercados regionais o seu diversificado "setor de mercado externo".

Conforme Singer, entre 1885 e 1930 as duas vias de "industrialização" estiveram severamente restringidas no Brasil, mas a unificação dos mercados em escala regional viabilizou o surgimento da indústria. "O café proporcionou a aglutinação de uma boa porção do território ao redor de São Paulo, que se tornou, por isso, o centro de acumulação do capital industrial" (1984, p. 214-215). Dado o caráter preponderantemente regional da indústria que surgiu e cresceu nesse período, parece-nos que havia diversos "centros" de acumulação industrial, com diferentes dimensões e graus de dinamismo, conforme as condições dos respectivos mercados regionais e suas articulações externas. É por isso que Singer pôde constatar

5 Além da acumulação comercial dispersa nos três níveis assinalados por Lagemann (1980, p. 128), os fatores propícios ao desenvolvimento do artesanato foram o isolamento dos mercados locais da região e a presença de colonos com experiência artesanal ou fabril trazida da Europa (TEJO, 1939). que "As zonas de colonização alemã e italiana, no Rio Grande do Sul e em Santa Catarina, passaram a encontrar na área cafeicultora um escoadouro para sua produção agropecuária, o que proporcionou a difusão do capitalismo e da Produção Simples de Mercadorias no interior daqueles Estados. Como resultado, surgiu no Sul, sobretudo em Porto Alegre, um significativo impulso industrializador" (1984, p. 215). Na verdade, o impulso industrializador verificado em Porto Alegre ao longo da Primeira República foi coetâneo ao impulso análogo que a atividade industrial recebia nas cidades da zona sul do estado.

O que ambos os "centros" regionais de acumulação industrial no Rio Grande do Sul tiveram em comum foi o caráter da produção agropecuária e agroindustrial destinada à exportação que, fosse da zona das colônias (banha, vinhos, fumo, feijão, farinhas etc.) ou da zona de pecuária (charque, conservas e arroz), destinava-se aos mercados regionais brasileiros de bens de consumo alimentar. A indústria surgiu com base em duas formações sócio-econômicas sub-regionais distintas cuja produção agropecuária de "exportação" alcançou, de modos também distintos, colocação principalmente nos mercados regionais brasileiros e muito secundariamente no mercado mundial ${ }^{6}$. A produção mercantil de alimentos in natura e processados da zona das colônias teve origem numa economia de subsistência formada por pequenos proprietários, que muito cedo se tornou abastecedora dos mercados locais e paulatinamente atingiria o mercado estadual e colocação nas outras regiões brasileiras em processo de urbanização. Já a produção agropecuária oriunda da outra zona do estado constituía no início da República a maior parcela das exportações estaduais (FONSECA, 1985, p. 282), ocupando desde o início do século XIX um lugar relevante nos mercados das demais regiões brasileiras, no caso dos produtos da pecuária, da mesma forma como com o arroz (embora este somente a partir dos anos 1910).

A conjugação dessas duas formações sub-regionais, ambas distintas da lavoura agro-exportadora e monocultura e que tampouco se apoiavam

\footnotetext{
6 Nas três primeiras décadas do século XX, as exportações ao mercado mundial responderam geralmente por menos de um terço das exportações totais da economia gaúcha (ALMEIDA, 1992, tabela III-1, dados para 1901, 1915, 1921, 1925 e 1928).
} 
nas correntes mais dinâmicas e instáveis do mercado mundial, materializou-se em patamar superior a partir da República, quando as ferrovias e a navegação fluvial integraram o mercado regional. Configurou-se uma região singular no contexto da República dos "Estados Unidos do Brasil"7. Mesmo o latifúndio na região sul esteve vinculado, através da pecuária, à produção para o mercado interno, sem ser essencialmente escravista como o foram as charqueadas ${ }^{8}$. Ao lado dessa formação social, floresceu outra, baseada na pequena propriedade agrícola. Em conjunto elas conferiram ao Rio Grande do Sul uma notável diversificação produtiva (TEJO, 1939), além da verdadeira "inovação social" que representava a presença de uma classe média rural, cujo peso econômico e social ascendia vertiginosamente (TARGA, 1996b). Essa diversidade teria de resultar também numa formação industrial híbrida ${ }^{9}$, caracterizada por uma maior fragmentação do capital, o que também ocorria na esfera comercial.

A sociedade gaúcha experimentou um processo peculiar de transição para as relações capitalistas de produção, marcado pela presença da pequena propriedade da terra e pela fragmentação do capital comercial e industrial. A questão nuclear dessa transição foi a passagem da mão-de-obra escrava para o trabalho assalariado, que exigiu a conformação de um mercado de trabalho livre e a elaboração de novas formas de dominação do capital sobre o trabalho (PESAVENTO, 1989).

Enquanto em São Paulo a imigração promovida pelos interesses do café deu início à formação do mercado de trabalho livre nas últimas décadas do século XIX, no Rio Grande do Sul a imigração

\footnotetext{
7 Para uma discussão sobre o conceito de região em conexão com o território, o Estado e a cultura regionais, ver Albuquerque (1998).

8 Sobre a importância da escravidão na economia gaúcha ver Cardoso (1977) e Targa (1996c).

9 Referimo-nos a uma estrutura industrial em que ao lado dos muitos estabelecimentos pequenos e mesmo pré-fabris, ocorria também a presença da grande indústria. Se é verdade que isso pode ser dito de outras indústrias regionais, inclusive a paulista, a característica foi ainda mais acentuada no Rio Grande do Sul. "Em síntese, a evolução da indústria gaúcha permite destacar dois momentos: a industrialização regionalizada e a industrialização nacional-internacionalizada. Resulta daí que a indústria no Estado, como se apresenta hoje, não pode ser entendida como um corpo homogêneo" (LAGEMANN, 1980, p. 117).
}

já vinha ocorrendo desde o início do século XIX, com outras finalidades, permitindo aos imigrantes (em uma ou duas gerações de seus descendentes) estabelecerem-se como proprietários rurais. O provimento de força de trabalho à indústria dependeu da expansão demográfica da zona colonial, onde a alta taxa de natalidade, a queda da fertilidade do solo e a limitação das terras determinaram um êxodo progressivo ao meio urbano e, mais tarde, também para outras regiões brasileiras. Na zona sul do estado, a liberação de força de trabalho do setor pecuário deveu-se ao cercamento das terras e ao uso das ferrovias no transporte do $\operatorname{gado}^{10}$. Desse modo, observaramse distintos processos de constituição do mercado de trabalho para a indústria. Na região de São Paulo transcorreu aceleradamente esse processo, que foi amplamente determinado pela rápida introdução de um elemento externo ao desenvolvimento demográfico regional: o ingresso maciço de trabalhadores imigrantes despossuídos, que transformou radicalmente a estrutura social em poucas décadas, fornecendo também os primeiros braços assalariados da emergente indústria paulista. No Rio Grande do Sul, a constituição do mercado de trabalho industrial foi progressiva, dependendo do desenvolvimento endógeno da estrutura social, que experimentava uma transição mais lenta para as relações capitalistas de produção. O mercado de trabalho também se constituía com maior dificuldade, observando-se uma escassez relativa de força de trabalho para a indústria, o que contribuiu para configurar um padrão distinto de relações industriais de trabalho.

\section{ESTRUTURA INDUSTRIAL, EMPREGO, SALÁRIOS E PRODUTIVIDADE EM 1920}

A indústria sul-rio-grandense na Primeira República, como toda a indústria nacional, era principalmente uma indústria de bens de consumo nãoduráveis na qual os três principais gêneros (alimentação, têxtil, vestuário e calçados) perfaziam cerca de dois terços da produção industrial. No país, a indústria ocupava cerca de 300 mil pessoas, sendo 1/3 em São Paulo e 1/10 no Rio Grande do Sul. Entretanto, já em 1920 essa era uma indústria muito concentrada, com um peso amplamente majoritário dos "grandes" estabelecimen-

\footnotetext{
10 Também a "pacificação" dos conflitos de fronteira e da política regional contribuíram para reduzir a necessidade de peões nas estâncias (ALMEIDA, 1996, p. 98).
} 
tos (mais de 100 operários) na produção e no emprego (tabela 1). Embora a maioria dos estabelecimentos $(80 \%)$ tivesse 9 ou menos operários empregados, mais da metade dos operários estava empregado pelos estabelecimentos "grandes" (eles eram 43 no Rio Grande do Sul e 145 em São Paulo).

Ocupando em média 3,3 operários, os pequenos estabelecimentos podem ser considerados em geral como negócios não-capitalistas, empregando preponderantemente mão-de-obra familiar e tendo o consumo como finalidade principal da produção (produção mercantil simples). No Rio Grande do Sul, os pequenos estabelecimentos eram responsáveis por $1 / 5$ do emprego de operários (1/ 8 em SP). Em decorrência disso e também do maior fracionamento da propriedade industrial, havia 10 operários para cada proprietário $(15 \mathrm{em}$ $\mathrm{SP}$ ), indicando um menor grau de comando do capital sobre o trabalho na produção industrial. $\mathrm{O}$ desenvolvimento industrial sul-rio-grandense dava lugar, na margem, para o estabelecimento de pequenos proprietários, capitalistas ou não.

Apesar disso, tanto numa região como na outra, os "grandes" estabelecimentos representavam efetivamente a grande indústria, com seus processos de trabalho definidos pela ampla utilização de máquinas e equipamentos importados. Além disso, a indústria expandia-se a um ritmo "espetacular" nas duas regiões ${ }^{11}$. De 1900 a 1904 dobrou o número de estabelecimentos. Desde então até 1909 cresceu em 50\% e de 1910 a 1920 triplicou no Rio Grande do Sul e ainda um pouco mais em São Paulo. Essa expansão determinava uma forte pressão de demanda sobre o mercado de trabalho.

Enquanto em São Paulo o mercado de trabalho livre e mesmo o capitalismo surgiram no campo com a lavoura cafeeira, no meio rural gaúcho era menor a extensão das relações de assalariamento. O mercado de trabalho constituiu-se paralelamente ao processo de urbanização, observando-se na região sul-rio-grandense um maior diferencial entre os salários urbanos e rurais do que o observado na outra região. A presença de estrangeiros entre os trabalhadores industriais nas cidades, que

\footnotetext{
11 A expressão é de Sérgio Silva (1986, p. 71-85) para caracterizar o ritmo de crescimento da indústria brasileira no início do século, sendo também aplicável às indústrias regionais tomadas isoladamente.
}

era de $28 \%$ em Porto Alegre e de $51 \%$ em São Paulo, é um índice da maior lentidão na formação do mercado regional de trabalho industrial, que se caracterizava ainda pela menor participação das mulheres entre os operários, de apenas $20 \%$ no Rio Grande do Sul (31\% em São Paulo).

Por efeito da restrita oferta de forças de trabalho e também da composição do emprego industrial por gênero, o salário médio diário era $6,3 \%$ maior na indústria gaúcha, em comparação com a paulista, onde a maior inserção das mulheres rebaixava a média salarial ${ }^{12}$. Embora a diferença nominal de salários médios diários fosse pequena, o custo de vida era inferior no Rio Grande do Sul, implicando uma menor pressão para a inserção das mulheres no mercado de trabalho formal. Ademais, isso aumentava a dependência da família em relação ao emprego do homem e o patronato industrial procurou valer-se dessa condição para estreitar os vínculos com sua força de trabalho, privilegiando o emprego de trabalhadores homens casados (PESAVENTO, 1988).

O patronato industrial do Rio Grande do Sul enfrentou a relativa escassez de força de trabalho através da ampla utilização de práticas assistencialistas (moradia, escola, assistência médica, fundos de pensão), associadas a um forte discurso ideológico que afirmava a compatibilidade dos interesses de classe e procurava desestimular a autoorganização dos trabalhadores. Havia uma preocupação sistemática em disfarçar a dominação do capital sobre o trabalho, o que era facilitado pelo envolvimento dos proprietários junto ao trabalho fabril (PESAVENTO, 1988).

$\mathrm{Na}$ indústria gaúcha foi necessário que as condições de exploração da força de trabalho fossem atenuadas em vista da efetiva disputa por trabalhadores entre os industriais. Aquelas práticas foram eficazes no sentido de submeter os trabalhadores e vinculá-los às fábricas, ensejando um desempenho produtivo superior e também melhores condições de trabalho.

Cabe avaliar o impacto dessas distintas condições dos mercados de trabalho sobre o desempenho das indústrias regionais. Na indústria gaúcha,

\footnotetext{
12 Podemos considerar que essa maior inserção refletia uma maior mercantilização da força de trabalho em São Paulo, ampliando sua oferta e ocorrendo provavelmente pela necessidade de ampliar a renda familiar.
} 
os custos salariais (salários e ordenados por empregado/ano) eram $10 \%$ maiores que na indústria paulista. Entretanto, isso não prejudicou o desenvolvimento industrial, pois a produtividade do trabalho (VTI/empregado) era 14\% superior (tabela 6). Atribuímos isso em parte à maior intensidade de capital (máquinas e utensílios por operário, que era $25 \%$ superior na indústria sul-rio-grandense), mas também às condições de trabalho e às formas de subordinação e enquadramento da força de trabalho utilizadas pelo patronato industrial gaúcho. Assim, a diferença de produtividade relativa mais que compensava os custos salariais mais elevados, de modo que a repartição do valor agregado industrial entre salários mais ordenados e lucro bruto era equivalente nas duas regiões (tabela 7).

Existem, portanto, fortes indicações de que a burguesia industrial gaúcha buscou outras formas de garantir suas margens de lucro, visto que simplesmente não podia proceder como sua congênere paulista, que pagava salários mais baixos e baseava seu desempenho em piores condições de trabalho ${ }^{13}$.

A indústria gaúcha constituiu-se e expandiuse no início do século com base num mercado de trabalho restrito, operando em condições próximas ao pleno emprego da força de trabalho de que podia dispor ${ }^{14}$. Diante da disputa pela força de trabalho, os industriais gaúchos adotaram práticas assistencialistas de cunho ideológico, que ensejaram relações de trabalho com menor grau de conflito, bem como melhores condições de trabalho e remuneração para os trabalhadores. Essa

\footnotetext{
13 Isso não se expressava, entretanto, numa maior rentabilidade da indústria gaúcha. Essa rentabilidade era inferior à da indústria paulista, seja quanto à margem ou quanto à taxa de lucro. As razões para tanto resumem-se da seguinte forma. Mesmo com uma divisão do valor agregado entre salários+ordenados e excedente bruto equivalente nas duas regiões, esse valor era menor no Rio Grande do Sul como proporção do VBP. A indústria paulista, mais diversificada, operava com maior agregação de valor. Na primeira região, era proporcionalmente mais elevado o peso da indústria da alimentação (2/3 do capital empregado no conjunto da indústria; 1/4 em São Paulo), que possuía baixa agregação de valor e também um elevado montante de capital empregado, graças ao grande volume de estoques. Isso rebaixava a margem de lucro e a taxa de lucro do conjunto da indústria gaúcha. Ver Herrlein \& Dias (1993, p. 285).
}

14 Não podemos aqui considerar na sua dimensão devida as características da organização do operariado industrial, marcada pela presença de lideranças socialistas e por uma situação parece ter condicionado o desempenho da indústria gaúcha de modo a ampliar os níveis de utilização de máquinas e utensílios, bem como a produtividade do trabalho. A escassez de força de trabalho para a indústria, combinada ao caráter incipiente da organização da emergente classe operária e ao êxito da burguesia industrial em subordinar os trabalhadores fabris, deram lugar a um certo padrão de desenvolvimento industrial, apoiado simultaneamente em índices superiores de produtividade e de intensidade de capital, e em melhores condições de trabalho e remuneração, em comparação com o padrão de desenvolvimento da indústria paulista.

\section{DE 1920 A 1950: PERMANÊNCIAS E DE- FASAGEM $^{15}$}

Ainda antes de 1930 decaiu a inserção externa da indústria sul-rio-grandense, especialmente dos gêneros que utilizavam matérias-primas importadas, como a têxtil de algodão. Dessa forma, a indústria teve seu caráter regional acentuado ao longo dos anos, perdendo mercados anteriormente conquistados fora do estado (REICHEL, 1979, p. 274).

forte influência anarquista até 1917. Aqui basta assinalar que, no Congresso Operário de 1913, realizado no Rio de Janeiro, os delegados da Federação Operária do Rio Grande do Sul (FORGS) concederam entrevista ao jornal "A Época” na qual, além de afirmar sua adesão à COB (Confederação Operária do Brasil, de orientação anarquista), responderam a várias perguntas, entre elas as seguintes. "P.: Tem havido muitos movimentos grevistas dirigidos pela Federação? R.: Sim, alguns e na maioria vitoriosos. P.: São boas as condições dos trabalhadores do RGS, especialmente os de P. Alegre? R.: Sim, de certo tempo a esta parte, 3 a 4 anos, tem se desenvolvido progressivamente o trabalho, principalmente na capital, notando-se até em algumas artes e ofícios falta de trabalhadores" (apud PETERSEN \& LUCAS, 1992, p. 174). A "bolsa de trabalho" mantida pela FORGS habitualmente encontrava colocação para os operários que buscavam emprego.

15 Chamo a atenção do leitor para a limitação da análise que segue enquanto uma abordagem do mercado de trabalho da indústria. A discussão desse objeto é apenas delineada neste trabalho, em suas determinações associadas ao desenvolvimento econômico e demográfico da região, em particular à acumulação industrial. Propomos uma consideração sobre a apropriação do produto industrial. Um tratamento adequado do mercado de trabalho regional enquanto objeto amplamente determinado, implicará a investigação das relações entre as classes industriais (e dessas com as demais classes e o Estado) e a consideração do custo de vida, entre outros aspectos. 
No entanto, após as conjunturas de crise do final dos anos 1920 e início dos 1930, o mercado regional continuou a expandir-se, fornecendo uma base expressiva para a produção industrial diversificada de bens de consumo não-durável e bens intermediários. Com base em matérias-primas locais, desenvolveram-se as indústrias de alimentação, bebidas, fumo, minerais não-metálicos, tecidos de lã, calçados, madeira e mobiliário, vestuário etc. A expansão do mercado regional continuava a ser viabilizada pelas vendas de produtos agropecuários e derivados aos mercados do centro do país ${ }^{16}$. Diante da crise externa, a economia gaúcha estreitava seus vínculos mercantis com os mercados internos ao país, beneficiando-se agora não mais dos impulsos derivados indiretamente das exportações cafeeiras, mas do dinamismo da economia paulista, que também impulsionava outras economias regionais importadoras da produção sul-rio-grandense (ALMEIDA, 1993). As exportações inter-regionais do Rio Grande do Sul expandiram-se a taxas médias anuais de 4,3\% entre 1928 e 1939 e de 7,8\% desde esse ano até 1950 (idem, 1993, p. 211) ${ }^{17}$.

De outra parte, a expansão da indústria paulista não chegava a ameaçar o mercado regional da indústria sul-rio-grandense ${ }^{18}$. Essa circunstância tornou possível uma evolução da estrutura dessa indústria até 1950 com uma crescente participação, no emprego e na produção industrial, de estabelecimentos de escala artesanal e capitalistas pequenos e médios (tabela 1).

Antes de proceder à análise da expansão dessa indústria e da evolução de seu mercado de trabalho, convém estabelecer nosso entendimento so-

16 Essa evolução foi desigual entre os dois subsistemas econômicos estaduais, atingindo maior dinamismo para a produção agropecuária colonial e a capitalista do arroz, visto que a pecuária teve uma crise persistente nos anos 1930 (PESAVENTO, 1980). Contudo, os três segmentos citados beneficiaram-se nos mesmos anos de uma evolução muito favorável dos preços (BRUM TORRES, 1983). Segundo Singer, Porto Alegre deve ter assumido a liderança industrial do estado de 1920 em diante ou mesmo antes (1977, p. 174).

17 Nos mesmos períodos, as importações de São Paulo oriundas do Rio Grande do Sul cresceram a uma base anual de 6,7\% e 9,3\% (ALMEIDA, 1993, p. 212).

18 Supomos que a indústria paulista contava com a expansão ainda mais acelerada de seu próprio mercado regional e de outras regiões mais próximas. Sendo assim, não surpreen- bre o caráter da articulação de toda a economia regional sul-rio-grandense com os mercados que lhe eram exteriores. Se, de um ponto de vista "nacional", os anos 1930 podem ser considerados como de mudança para um desenvolvimento econômico endógeno (FURTADO, 1982) e de início de um processo de industrialização restringida (CARDOSO DE MELLO, 1982), do ponto de vista daquela economia regional, precocemente voltada para o mercado interno brasileiro, esse período não assinala qualquer descontinuidade relevante, pois permaneciam como sua fonte externa de dinamismo os mercados de diversas regiões, sobretudo do Sudeste ${ }^{19}$. Tinha continuidade o padrão de desenvolvimento da economia regional constituído ao longo da Primeira República, ampliando-se suas exportações inter-regionais de produtos agropecuários e agroindustriais, enquanto a indústria assumia um caráter ainda mais regional ${ }^{20}$.

Nesse sentido, podemos considerar que a economia gaúcha continuava a se articular com o "mercado nacional" como uma economia à parte, com sua própria unidade interna, mesmo que vinculada à demanda do "centro". Vale dizer, apenas se iniciara o processo de integração do mercado

de que Luciano Martins tenha assinalado a falta de perspectiva nacional de mercado da burguesia industrial paulista, cuja indústria, substitutiva de importações, já produzia para camadas de consumidores de rendas altas e médias de seu próprio mercado regional (apud TARGA, RIBEIRO \& HERRLEIN JR., 1998). Também Almeida admite restrições às exportações inter-regionais da indústria paulista, pois devido à "elevada utilização da capacidade produtiva industrial, é natural que as transações com as mercadorias manufaturadas tenham se concentrado no âmbito regional em detrimento das vendas para outras economias regionais do País" (1993, p. 162).

19 Tal continuidade permitiu certas abordagens da economia gaúcha, como a de Souza (1973), que a analisou conforme um mesmo modelo primário-exportador desde o século XIX até os anos 1960, e a de Accurso et alii (1965) que a discutiram como se fosse uma economia fechada e isolada (cf. TARGA, 1989).

20 Para um conceito de padrão de desenvolvimento, veja-se FEE (1976, p. 139), em conformidade com Tavares (1998). Se tivermos em mente uma noção mais ampla desse padrão, de modo a incluir as determinações a que Lipietz (1988) e outros autores franceses chamam de "modo de regulação", teremos maior dificuldade para estabelecer a referida continuidade, pois a partir de 1930 a reorganização do poder de Estado esvaziou a esfera regional, cujas políticas econômicas haviam sido particularmente importantes para a configuração e o desenvolvimento da economia gaúcha no período anterior. 
nacional, mantendo-se uma conexão "em bloco" dessa economia regional com os demais mercados regionais brasileiros, enquanto uma totalidade econômica que seguia um processo próprio de desenvolvimento ${ }^{21}$. $O$ grau de unidade interna dessa economia regional manifestava-se pela solidariedade existente entre o desempenho do setor agropecuário e o da indústria, fosse através do fornecimento de matérias-primas, fosse através do dinamismo do mercado regional para a produção industrial ${ }^{22}$. Essa economia regional relativamente integrada, ainda que constituísse apenas uma unidade incompleta, era parte do todo da economia nacional, ao lado das outras partes, as demais economias regionais (TARGA, 1984) 23 .

A indústria sul-rio-grandense teve seu mercado preservado da concorrência com outras indústrias regionais, pelo menos até 1955 . É correto portanto afirmar que "Como resultado da escassa concorrência inter-regional no mercado de produtos manufaturados, não se pode dizer que, durante a industrialização restringida, a indústria no Brasil se organizasse em ramos constituídos nacionalmente mas que, ao contrário, os mesmos, na maioria dos casos, tinham um forte caráter regional. Isto quer dizer que era principalmente

21 Para uma discussão sobre a categoria da totalidade econômica, ver Targa (1982). O mesmo autor (TARGA, 1988) propõe que todo o período $1930-60$ seja considerado como de sobrevida dos mercados regionais. Acreditamos que isso é particularmente verdadeiro para a economia sulrio-grandense, devido à singularidade de sua trajetória anterior de desenvolvimento. O que ocorre entre 1930 e 1955 é uma rearticulação das economias regionais numa nova divisão inter-regional de trabalho, polarizada pela economia paulista.

22 Decorre daí que se tenha argumentado com certo exagero que, pelo menos até 1945 , a economia gaúcha apresentasse um "moto próprio", padecendo posteriormente, e isso é correto, de uma "desarticulação interna" (FEE, 1976, p. 140-3). Pesavento considera que a "diversificada economia gaúcha” possuía pelo menos até o final da Segunda Guerra Mundial uma integração entre seus setores e "apresentava uma certa coerência interna e um moto próprio, que depois perderia, na nova etapa de acumulação em que o país iria ingressar na década de 50” (1985, p. 91).

23 Note-se que a hierarquia entre essas partes deve ser considerada como função das dimensões de seus respectivos mercados regionais e do caráter dinâmico principal ou subsidiário de suas articulações; portanto, uma hierarquia posta por um todo cujas partes não eram ainda os ramos nacionais da produção, especialmente da produção industrial. do processo competitivo intra-regional que decorriam as imposições, vigentes em cada economia regional, determinantes do tamanho médio dos capitais, da produtividade do trabalho, da rentabilidade média, das taxas de expansão setoriais etc." (ALMEIDA, 1993, p. 168) ${ }^{24}$.

Não deve surpreender, portanto, que o Valor Bruto da Produção industrial sul-rio-grandense tenha se expandido entre 1919 e 1939 a uma base anual de 5,3\% ao ano, acentuando-se esse crescimento para a taxa anual de $6,0 \%$ no período 1939 49 (tabela 3$)^{25}$. Nos mesmos períodos, a população do estado cresceu a taxas anuais médias de $2,1 \%$ e $2,3 \%$, enquanto o número de pessoas ocupadas na indústria expandiu-se em $4,3 \%$ e $5,4 \%$. Os dados indicam que a base do mercado regional permitiu considerável expansão da indústria sul-rio-grandense, embora em ritmo inferior ao da indústria paulista, situando-se as maiores diferenças no primeiro sub-período.

Esse crescimento da indústria regional fez-se de modo a reduzir o seu grau de concentração técnica e econômica (tabela 1). A cada recenseamento da indústria, decaiu o tamanho do estabelecimento médio em termos de pessoas ocupadas, enquanto crescia a participação dos estabelecimentos pequenos (artesanais) e médios na ocupação total ${ }^{26}$. Assim, embora a indústria sul-rio-

24 Não obstante tal afirmativa, Almeida sustenta, conforme Cano (1985), que a integração do mercado nacional já estava estabelecida no período 1930-55. Entretanto, também Castro (1971, p. 120-9) sustenta que havia um isolamento da economia gaúcha até os anos 1950, enquanto Souza (1973, p. 85) refuta os argumentos de Singer (1977) em favor de uma suposta integração do mercado gaúcho ao do Sudeste por via ferroviária em 1910, argumentando corretamente que em 1940 ainda não estava definida a situação dos ramos industriais em termos nacionais.

25 Nos dois subperíodos a indústria paulista expandiu o valor de sua produção a 7,8\% em bases anuais. Por força do peso de São Paulo, a taxa nacional também é superior a da indústria sul-rio-grandense. Segundo Almeida (1993, tabela III-15), os dados de expansão do produto (VTI) indicam que essa indústria regional expandiu-se num ritmo equivalente ao observado no agregado Brasil exclusive São Paulo.

26 Certamente que podemos considerar possíveis discrepâncias de abrangência entre os recenseamentos industriais (que poderiam estar se tornando mais completos), tal como fez Paul Singer em relação aos levantamentos de informações da indústria de 1889, 1907 e 1920 (1984, p. 213). Ocorre que, segundo as especificações introdutórias aos recenseamentos de 1920, 1940 e 1950, não há evidências de que 
grandense tivesse expandido sua produção industrial em ritmo inferior à de São Paulo e equivalente às demais regiões brasileiras tomadas em conjunto, o número de estabelecimentos recenseados naquela indústria regional ampliou-se na mesma proporção que nesses dois agregados regionais até 1940 e proporcionalmente mais desse ano até 1950 (132\% em comparação a $80 \%$ em São Paulo) ${ }^{27}$. E podemos considerar a expansão relativa do número de estabelecimentos industriais (fabris, manufatureiros e artesanais) existentes em diferentes regiões como um indicador da distribuição da propriedade industrial.

Isso parece indicar que, para o Rio Grande do Sul, até 1950, permanecia válida a afirmativa de
Singer para a indústria brasileira antes de 1930: "[O]s dados revelam [...] uma ampla atividade manufatureira, realizada, em grande parte, numa miríade de pequenos estabelecimentos, organizados sob a forma de Produção Simples de Mercadorias, ou seja, operados por seus donos e familiares, com o eventual auxílio de alguns empregados" (SINGER, 1984, p. 213).

Entretanto, lado a lado a esses estabelecimentos, ampliou-se também o contingente de estabelecimentos capitalistas ocupando de 10 a 100 operários, indicando a continuidade do padrão de desenvolvimento da indústria gaúcha, com uma distribuição mais ampla da propriedade industrial e um processo de acumulação menos concentrador.

Tabela 1. Distribuição dos estabelecimentos industriais e dos operários neles ocupados e tamanho médio dos estabelecimentos, segundo o número de operários, por faixas de ocupação de operários - Rio Grande do Sul, São Paulo - 1920, 1950



Fonte: dados brutos dos censos industriais de 1920 (1\%/09) e 1950 (1\%/01).

Nota: (1) as faixas para 1920 são inferiores em uma unidade.

Do ponto de vista da concentração técnica da ocupação (e da produção), parece ter ocorrido um

tenham se alterado os critérios de inclusão nos recenseamentos, sendo os três bastante amplos. De todo modo, para contornar o possível problema, utilizaremos a comparação regional com São Paulo como balizadora para algum eventual viés nos critérios dos censos. Essa observação é válida para diversas estatísticas industriais e demográficas, denotando, em seu tratamento, mais uma vantagem da utilização de uma perspectiva comparativa entre regiões. Para uma consideração dessa perspectiva em estudos de história regional, ver Targa (1991).

27 A relação entre o número médio de pessoas ocupadas por estabelecimento na indústria gaúcha e o mesmo número na retrocesso na indústria sul-rio-grandense. Provavelmente isso se verificou porque quase todos os estabelecimentos industriais operavam tendo como escala o mercado regional. O desenvolvimento industrial no Rio Grande do Sul prosseguia oferecendo uma margem crescente à expansão do número de pequenos e médios estabelecimentos capitalistas e mesmo da produção simples de mercadorias. Mantinha-se a maior divisão da proprie-

indústria paulista caiu de $72 \%$ para $53 \%$ e depois para $39 \%$, de 1920 a 1940 e 1950. Nos dois subperíodos esse número médio manteve-se inalterado para a indústria paulista, oscilando em torno de 23 pessoas. 
dade industrial nessa região, comparativamente a São Paulo, e um menor grau de expropriação dos produtores. Enquanto em 1920 havia naquela indústria regional 101 proprietários para cada 1000 operários ocupados e 64/1 000 na indústria paulista, para 1950 dado análogo assinala 179 e 72 , respectivamente ${ }^{28}$. Isso afetava o perfil da ocupação, de modo que, em 1950, na indústria sul-rio-grandense $76,1 \%$ dos ocupados eram operários enquanto $13,7 \%$ estavam na "administração" dos estabelecimentos $(82,6 \%$ e $6,0 \%$ na indústria paulista).

Fernando Henrique Cardoso parecia estar correto quando procurou explicar en passant certas características do desenvolvimento econômico do Rio Grande do Sul no século XX. "[A] forma pela qual se realizou a integração do imigrante na sociedade gaúcha (como proprietários) foi responsável tanto pelo surto rápido de progresso industrial no fim do século XIX e início do século XX como pelas proporções relativamente modestas que a indústria gaúcha alcançou nos meados do século XX. Atividade familiar, semi-artesanal no início, permitiu, mais tarde, oficinas e atelliers de ótima qualidade técnica, mas erigiu-se como um obstáculo para a construção da 'grande indústria'. Isto tanto porque persistiu o 'problema da mão-deobra' (a escassez de trabalhadores não proprietários dos meios de produção), como porque a formação de mentalidade de 'grande empresário' foi dificultada graças ao grande número e ao êxito de pequenos proprietários" (CARDOSO, 1977, p. $212)^{29}$.

$\mathrm{Na}$ indústria sul-rio-grandense, as firmas individuais ou sociedades formadas por pessoas físicas, que em 1920 representavam $98 \%$ dos estabelecimentos, em 1950 ainda ultrapassavam $80 \%$,

\footnotetext{
28 Os dados para 1950 referem-se à categoria de ocupados na "administração", que inclui proprietários, sócios e diretores.

29 Mesmo aqui, FHC merece alguns reparos. Como veremos adiante, é muito provável que não tenha persistido a escassez de trabalhadores não-proprietários. Tal escassez, verificada pelo menos até os anos 1920, não foi um obstáculo ao surgimento da grande indústria, que, como vimos, efetivamente transcorreu no Rio Grande do Sul durante a Primeira República. Os problemas com que se defrontou a "construção" da grande indústria, se entendermos por isso a expansão do número de "grandes" estabelecimentos fabris, não decorreram tanto da mentalidade dos pequenos proprietários ou de seu eventual "êxito", quanto da reduzida pos-
}

embora houvesse decaído sua importância na ocupação em favor das sociedades anônimas, de capital, mistas e outras de caráter não-pessoal, cujo peso na ocupação de operários cresceu de $31 \%$ para $59 \%$ no mesmo período ${ }^{30}$. Esse relativo avanço na organização empresarial dos negócios industriais, expresso pela mudança na distribuição dos operários ocupados entre os estabelecimentos com diferentes formas de constituição jurídica, foi observado concomitantemente à assinalada regressão na concentração técnica da estrutura industrial, não se materializando portanto numa ampliação do peso dos grandes estabelecimentos capitalistas nessa estrutura. Provavelmente, foram os estabelecimentos de porte médio que, ampliando sua participação na ocupação, passaram também a se organizar como sociedades anônimas ou sob outras formas não-pessoais.

No período em foco ocorreram algumas mudanças na estrutura do produto da indústria gaúcha, segundo os gêneros industriais (tabela 2). Até 1949, expandiram-se com maior intensidade as "indústrias de bens intermediários", principalmente os gêneros metalúrgico, químico e de madeira. A indústria mecânica respondeu pela ampliação do grupo de "indústrias de bens de capital e de consumo duráveis". O decréscimo relativo das "indústrias de bens de consumo não-duráveis" na estrutura do produto deveu-se principalmente à queda da participação do principal grupo de gêneros, de alimentação, bebidas e fumo (cai de 55,8\% em 1919 para $44,4 \%)$ e da têxtil $(12,1 \%$ para $5,9 \%$ ), que não foi compensado pela ampliação do peso da indústria de vestuário e calçados (de $5,1 \%$ para $7,5 \%$ ). A amplitude e o sentido das mudanças ocorridas na estrutura da indústria sulrio-grandense equivalem-se ao da indústria do conjunto das regiões brasileiras, excluindo-se São Paulo, região na qual as mudanças na indústria

sibilidade de concentrar e/ou centralizar capital na escala adequada.

30 Para avaliar-se o grau dessas mudanças na organização dos negócios industriais no Rio Grande do Sul, considere-se os dados para a indústria paulista. São semelhantes quanto à proporção de estabelecimentos registrados em nome pessoal, que foi de $92 \%$ em 1920 e $71 \%$ em 1950, enquanto a participação dos demais estabelecimentos ( $\mathrm{S} / \mathrm{As}$ e outras organizações não-pessoais) no emprego de operários evoluiu no mesmo sentido, ainda que sempre maior na indústria paulista, sendo de 49\% em 1920 e de 79\% em 1950. 
apresentaram uma amplitude muito maior, transcorrendo no sentido de complementar a malha industrial através da implantação das indústrias de bens de produção e de consumo duráveis.

Tabela 2. Estrutura da indústria, segundo o Valor da Transformação Industrial - Rio Grande do Sul, São Paulo, Brasil exclusive SP $(1919,1939,1949)$

\begin{tabular}{l|c|c|c|c|c|c|c|c|c}
\hline \multirow{2}{*}{$\begin{array}{l}\text { GRUPOS DE INDÚSTRIA, POR } \\
\text { PREDOMÍNIO DA PRODUÇÃO }\end{array}$} & \multicolumn{3}{|c|}{ Rio Grande do Sul } & \multicolumn{3}{c|}{ São Paulo } & \multicolumn{3}{c}{ Brasil exclusive SP } \\
\cline { 2 - 11 } & $\mathbf{1 9 1 9}$ & $\mathbf{1 9 3 9}$ & $\mathbf{1 9 4 9}$ & $\mathbf{1 9 1 9}$ & $\mathbf{1 9 3 9}$ & $\mathbf{1 9 4 9}$ & $\mathbf{1 9 1 9}$ & $\mathbf{1 9 3 9}$ & $\mathbf{1 9 4 9}$ \\
\hline $\begin{array}{l}\text { GRUPO I - Bens de } \\
\text { consumo não-duráveis }\end{array}$ & 78,6 & 70,3 & 64,4 & 74,3 & 62,3 & 55,5 & 79,8 & 71,1 & 65,7 \\
\hline GRUPO II - Bens intermediários & 20,9 & 26,9 & 31,7 & 22,7 & 26,0 & 33,7 & 18,9 & 25,8 & 29,8 \\
\hline $\begin{array}{l}\text { GRUPO III - Bens de capital e de } \\
\text { consumo duráveis }\end{array}$ & 0,5 & 2,8 & 3,9 & 3,0 & 11,7 & 10,8 & 1,3 & 3,1 & 4,5 \\
\hline
\end{tabular}

Fonte: Cano (1985, p. 96).

No Rio Grande do Sul, a produção industrial cresceu expressivamente mais que a população total e a que população urbana, sendo que aquele crescimento acelerou-se nos anos 1940, ampliando-se também o diferencial (tabela 3$)^{31}$. Os dados sugerem ser provável a expansão da parcela do mercado regional atendida pela indústria local ${ }^{32}$. Também é possível supor que se manteve a pressão de demanda por forças de trabalho na indústria, na medida que o emprego industrial também se ampliou mais aceleradamente que a população. Contudo, os dados não são conclusivos para o subperíodo até 1940 , pois, conforme as estatísticas demográficas, o contingente de ocupados em atividades industriais cresceu bem menos que a população, especialmente menos que a população ocupada (inclusive em Porto Alegre) e a urbana. Esse comportamento pode ser decorrente de dois fenômenos não necessariamente excludentes. Devido às diferenças de abrangência das classificações de "indústria" entre os dois recenseamentos (mais ampla no demográfico), poderia ter ocorrido nos anos de 1920 a 1940 uma expansão do emprego industrial stricto sensu maior que o de outras atividades tidas como "industriais" nos recenseamentos demográficos. Outra possibilidade seria a de que nesse período tivesse ocorrido um crescimento das ocupações industriais lato sensu significativamente menor que o de outras ocupações, tanto no Rio Grande do Sul como em Porto Alegre. Os dados da tabela 4 parecem confirmar essa última hipótese ${ }^{33}$.

Tabela 3. Taxas médias anuais de crescimento do VBP industrial, do Pessoal Ocupado na indústria e da População Total, Urbana e Ocupada - Rio Grande do Sul, Porto Alegre, São Paulo e cidade de São Paulo (1920, 1940, 1950) (em \%)

\begin{tabular}{c|c|c|c|c|c|c|c}
\hline \multirow{2}{*}{$\begin{array}{c}\text { Períodos } \\
(\mathbf{1})\end{array}$} & \multirow{2}{*}{ Região } & \multicolumn{2}{|c|}{ Dados da indústria } & \multicolumn{4}{c}{ Dados demográficos } \\
\cline { 3 - 8 } & VBP & $\begin{array}{c}\text { Pessoal } \\
\text { ocupado }\end{array}$ & PT & PU & $\begin{array}{c}\text { Pop.ocp. } \\
\text { (2) }\end{array}$ & $\begin{array}{c}\text { Pop.ocp. atv. } \\
\text { ind. (3) }\end{array}$ \\
\hline \multirow{3}{*}{$\begin{array}{c}\mathbf{1 9 2 0} a \\
1940\end{array}$} & RS & 5,3 & 4,3 & 2,1 & 3,0 & 3,2 & 1,0 \\
\cline { 2 - 8 } & P. Alegre & n.d. & n.d. & 2,1 & n.c. & 2,5 & 0,7 \\
\cline { 2 - 8 } & SP & 7,8 & 6,0 & 2,3 & n.c. & 3,5 & 3,2 \\
\hline
\end{tabular}

31 Note-se que, embora em São Paulo a expansão da produção industrial mantivesse um ritmo superior, nos anos 40 não ocorreu uma aceleração como no caso do Rio Grande do Sul.

32 No contexto da crise internacional, a indústria gaúcha mantinha-se isolada da concorrência da indústria paulista e podia ocupar o espaço de mercado local que antes era atendido por importações externas. Nosso plano de pesquisa pretende analisar as importações (inter-regionais e internacionais) do Rio Grande do Sul, cabendo acessar dados que permitam construir um índice de seu valor para os três pon- tos no tempo, além de uma breve consideração de sua pauta. 33 Não fosse pelas indicações em sentido contrário, que atestam no mesmo período uma acelerada expansão da produção industrial e, na década seguinte, também do emprego e da ocupação industrial, teríamos de aceitar sem ressalvas a forte assertiva de Darcy Ribeiro. Ao comentar a estagnação da zona de pecuária extensiva, Ribeiro afirma que "o Rio Grande do Sul experimentou um profundo processo de urbanização sem industrialização, vendo multiplicar-se nas grandes e pequenas cidades uma massa enorme de subocupados, de mendigos e prostitutas” (1995, p. 525). 


\begin{tabular}{|c|c|c|c|c|c|c|c|}
\hline 1920 a 1940 & S. Paulo & n.d. & n.d. & 4,2 & n.c. & 5,0 & 4,2 \\
\hline \multirow{4}{*}{$\begin{array}{c}1940 \mathrm{a} \\
1950\end{array}$} & $\mathrm{RS}$ & 6,0 & 5,4 & 2,3 & 3,2 & 2,2 & 4,6 \\
\hline & P. Alegre & 4,5 & 2,3 & 3,8 & n.c. & 4,8 & 4,6 \\
\hline & SP & 7,8 & 6,0 & 2,4 & n.c. & 2,7 & 6,5 \\
\hline & S. Paulo & 7,4 & 5,5 & 5,2 & n.c. & 6,5 & 6,3 \\
\hline
\end{tabular}

Fonte dos dados brutos: Censos industriais, demográficos e recenseamentos de 1920, 1940 e 1950. Os dados de produção foram deflacionados pelo deflator construído por Cano (1985, p. 322).

Notas: n.d.: dado não disponível; n.c.: dado não calculado; (1) os períodos para os dados de produção correspondem a 1919-1939-1949; (2) população ativa com mais de dez anos, com declaração de ocupação, exclusive ocupações indefinidas ou mal definidas, exclusive ocupações domésticas e escolares; apenas os dados para 1950 incluem os serviços domésticos remunerados; (3) atividades industriais de transformação, conforme definições dos censos demográficos, inclusive construção civil.

Entretanto, para os anos 1940, os dados de ocupação industrial nos dois recenseamentos são convergentes, indicando uma expansão do emprego industrial superior às da população total e urbana. Como o contingente total de ocupados nessa década expandiu-se muito lentamente, sugerindo uma redução da pressão de demanda sobre o mercado de trabalho em geral, é provável que as atividades industriais tenham cumprido um papel importante de absorver mão-de-obra frente à fraca expansão de outros setores. Essa hipótese não pode ser refutada pela análise da tabela 4 , que indica pelo menos uma estabilidade da participação da indústria na ocupação, embora cabendo ao setor de serviços o papel preponderante na geração de empregos.

Tabela 4. Distribuição dos ocupados com declaração de ocupação definida, segundo o setor de ocupação - Rio Grande do Sul, Porto Alegre, São Paulo e cidade de São Paulo $(1920,1940,1950)$ (em \%)

\begin{tabular}{l|c|c|c|c|c|c|c|c|c|c|c|c}
\hline \multirow{2}{*}{ SETORES } & \multicolumn{3}{|c|}{ RIO GDE. DO SUL } & \multicolumn{3}{c|}{ Porto Alegre } & \multicolumn{3}{c|}{ SÃO PAULO } & \multicolumn{3}{c}{ São Paulo } \\
\cline { 2 - 14 } & $\mathbf{1 9 2 0}$ & $\mathbf{1 9 4 0}$ & $\mathbf{1 9 5 0}$ & $\mathbf{1 9 2 0}$ & $\mathbf{1 9 4 0}$ & $\mathbf{1 9 5 0}$ & $\mathbf{1 9 2 0}$ & $\mathbf{1 9 4 0}$ & $\mathbf{1 9 5 0}$ & $\mathbf{1 9 2 0}$ & $\mathbf{1 9 4 0}$ & $\mathbf{1 9 5 0}$ \\
\hline Agropecuária e silvicultura & 68,3 & $\mathbf{6 7 , 9}$ & 59,5 & $\mathbf{1 6 , 4}$ & $\mathbf{4 , 7}$ & $\mathbf{2 , 9}$ & $\mathbf{6 5 , 4}$ & $\mathbf{5 8 , 3}$ & $\mathbf{4 2 , 3}$ & 6,7 & 2,9 & 1,7 \\
\hline Indústria extrativa (1) & 1,1 & 1,0 & 1,4 & 0,3 & 0,8 & 0,8 & 1,3 & 0,9 & 1,3 & 1,1 & 0,4 & 0,5 \\
\hline $\begin{array}{l}\text { Indústria de transformação } \\
\text { (2) }\end{array}$ & 14,2 & 9,3 & 11,8 & 36,5 & 25,7 & 25,1 & 17,3 & 16,3 & 23,4 & 53,3 & 45,4 & 44,2 \\
\hline Comércio (3) & 6,7 & 6,3 & 6,5 & 21,8 & 23,0 & 19,2 & 6,6 & 7,9 & 8,4 & 16,2 & 19,1 & 15,6 \\
\hline Serviços (4) & 6,2 & 10,6 & 16,8 & 14,7 & 31,0 & 41,2 & 7,5 & 13,0 & 21,9 & 17,0 & 23,3 & 33,3 \\
\hline Setor público (5) & 3,5 & 4,9 & 4,0 & 10,3 & 14,8 & 10,8 & 1,9 & 3,6 & 2,7 & 5,7 & 8,9 & 4,7 \\
\hline
\end{tabular}

Fonte: Censos demográficos.

Notas: (1) exploração do subsolo, em 1920; (2) inclusive construção civil; (3) inclui os bancos e os negócios imobiliários: (4) transportes e comunicações, profissionais liberais, atividades sociais, administração e ensino privados; exclusive as ocupações domésticas remuneradas; (5) administração pública, exército e segurança pública.

Observação: o total dos ocupados em consideração corresponde à população ativa com mais de dez anos, com declaração de ocupação, exclusive ocupações indefinidas ou mal definidas, exclusive ocupações domésticas e escolares; apenas os dados para 1950 incluem os serviços domésticos remunerados.

Diante de algumas indicações ambíguas, pouca coisa pode-se concluir para o subperíodo até 1940, havendo sinais de que haveria uma pressão geral de demanda sobre o mercado de trabalho, na medida em que o contingente total de ocupados expandiu-se mais rapidamente que a população total e urbana. Já na década de 1940, aquele contingente cresceu menos que a população total e sobretudo a urbana, aliviando-se a pressão de demanda sobre o mercado de trabalho e comportando-se o emprego industrial em sentido oposto, atuando a indústria como absorvedora de mãode-obra.

Principalmente depois de 1940, ocorreu a emigração de um amplo contingente demográfico do 
Rio Grande do Sul (FEE, 1977, p. 54; 1978, p. 71). Esse processo não chegou a prejudicar a oferta local de força de trabalho para a indústria, pois também acentuaram-se as migrações rural-urbanas internas à região (MEDEIROS, 1975). Antes de ser um problema, as emigrações inter-regionais permitiram conter a ampliação da pobreza urbana, dilatando para fora do Estado a fronteira de reprodução da agricultura familiar, que já es- barrava nos limites da estrutura agrária dual (esgotamento do solo na pequena propriedade e latifúndio pastoril consolidado, além de estagnado). Provavelmente esse mesmo processo modificou as antigas condições de uma relativa escassez de forças de trabalho para as ocupações urbanas, contribuindo para inibir a evolução dos salários, embora em grau muito menor do que se teria observado sem as emigrações inter-regionais.

Tabela 5. Parcelas feminina e de menores entre os operários - Rio Grande do Sul, São Paulo (1920-50)

\begin{tabular}{c|c|c|c|c}
\hline \multirow{2}{*}{ Anos } & \multicolumn{2}{|c|}{ Parcela feminina } & \multicolumn{2}{c}{ Parcela de menores } \\
\cline { 2 - 5 } & $\begin{array}{c}\text { Rio Grande do } \\
\text { Sul }\end{array}$ & São Paulo & $\begin{array}{c}\text { Rio Grande do } \\
\text { Sul }\end{array}$ & São Paulo \\
\hline $\mathbf{1 9 2 0}$ & $21,8 \%$ & $33,7 \%$ & $7,8 \%$ & $7,7 \%$ \\
\hline $\mathbf{1 9 4 0}$ & $23,3 \%$ & $34,0 \%$ & $14,2 \%$ & $18,2 \%$ \\
\hline $\mathbf{1 9 5 0}$ & $23,4 \%$ & $33,7 \%$ & $12,8 \%$ & $17,4 \%$ \\
\hline
\end{tabular}

Fonte: Censos industriais.

Não obstante essas modificações demográficas que tenderam a ampliar a oferta de forças de trabalho, aparentemente manteve-se o menor grau de mercantilização da capacidade de trabalho no
Rio Grande do Sul, se o avaliarmos pelas parcelas de mulheres e de menores entre os operários industriais (tabela 5).

Tabela 6. Índices de produtividade econômica e do custo salarial médio anual por empregado da indústria - Rio Grande do Sul, São Paulo e Brasil $(1919,1939,1949)$ (RS em 1919 = 100)

\begin{tabular}{c|c|c|c|c|c|c|c|c|c}
\hline \multirow{2}{*}{ Índices } & \multicolumn{3}{|c|}{ Rio Grande do Sul } & \multicolumn{3}{c|}{ São Paulo } & \multicolumn{3}{c}{ Brasil } \\
\cline { 2 - 10 } & 1919 & 1939 & 1949 & 1919 & 1939 & 1949 & 1919 & 1939 & 1949 \\
\hline VBP/Emp & 100 & 145 & 135 & 83 & 142 & 143 & 77 & 115 & 123 \\
\hline VTI/Emp & 100 & 132 & 128 & 88 & 123 & 154 & 79 & 112 & 130 \\
\hline EB/Emp & 100 & 127 & 123 & 87 & 116 & 143 & 77 & 107 & 122 \\
\hline S.O./Emp & 100 & 148 & 145 & 91 & 145 & 186 & 85 & 129 & 154 \\
\hline
\end{tabular}

Fonte dos dados brutos: Censos industriais de 1920, 1940 e 1950.

Notas: a) valores deflacionados conforme Cano (1985, p. 322); b) os índices correspondem à evolução das razões entre os montantes anuais do Valor Bruto da Produção, do Valor da Transformação Industrial, do Excedente Bruto (VTI menos S. O.) e de Salários e Ordenados (totais), nos anos indicados, e o número de empregados no ano imediatamente seguinte.

Até 1940, o custo salarial médio anual por empregado na indústria gaúcha manteve-se em patamar superior ao da indústria paulista, mas caiu muito a diferença, refletindo um incremento menor da produtividade (tabela 6). Ainda assim, esse custo salarial elevou-se proporcionalmente mais que a produtividade econômica, que ainda supe- rava a da indústria paulista ${ }^{34}$. Os dados de 194950 assinalam que ao longo de uma década houve a nítida reversão desse quadro. $\mathrm{O}$ custo salarial

34 Resulta daí que na indústria gaúcha, como também na paulista, ampliou-se a parcela de salários e ordenados no valor agregado da indústria, conforme indicado na tabela 7 . 
na indústria gaúcha caiu abaixo da média da indústria nacional, igualando-se seus níveis de produtividade, e bem abaixo do mesmo custo para a indústria paulista, que passava a ter uma produtividade muito superior. Parece, portanto, que o principal problema para uma evolução favorável dos salários na indústria gaúcha nos anos 1940 não foi a ampliação da oferta de forças de trabalho frente a uma supostamente fraca expansão industrial ou do emprego urbano em geral, pois o custo salarial médio caiu ligeiramente menos que a produtividade e manteve-se o nível da parcela salarial no produto (tabela 7). O maior problema parece ter sido a defasagem do desenvolvimento industrial sul-rio-grandense quanto aos ganhos de produtividade, que permitiram aumentos salariais em São Paulo e para a média da indústria nacional.

Tabela 7. Relações entre componentes do valor da produção: parcela do valor agregado (VTI) e parcela salarial (S. O.)

\begin{tabular}{c|c|c|c|c|c|c}
\hline \multirow{2}{*}{ Relação } & \multicolumn{3}{|c|}{ Rio Grande do Sul } & \multicolumn{3}{c}{ São Paulo } \\
\cline { 2 - 7 } & $\mathbf{1 9 1 9}$ & $\mathbf{1 9 3 9}$ & $\mathbf{1 9 4 9}$ & $\mathbf{1 9 1 9}$ & $\mathbf{1 9 3 9}$ & $\mathbf{1 9 4 9}$ \\
\hline VTI/ VBP & $42,2 \%$ & $38,4 \%$ & $40,1 \%$ & $44,7 \%$ & $36,6 \%$ & $45,4 \%$ \\
\hline S.O./ VTI & $25,1 \%$ & $28,1 \%$ & $28,3 \%$ & $25,9 \%$ & $29,4 \%$ & $30,4 \%$ \\
\hline
\end{tabular}

Fonte: dados brutos dos Censos industriais.

\section{CONCLUSÃO}

É possível concluir que o padrão de desenvolvimento industrial regional sul-rio-grandense preservou-se em largos traços e aprofundou algumas de suas características diferenciadoras do padrão paulista no período 1920-50. Porém, o acréscimo de produtividade que aquela indústria regional logrou obter foi insuficiente para manter os elevados níveis relativos de salários, que talvez tenham sido prejudicados pela ampliação da oferta de trabalho. A defasagem nos acréscimos de produtividade até 1940 transcorreu quase que in- tegralmente pelo maior incremento dos custos de matérias-primas e insumos por empregado observado na indústria paulista. Na década seguinte, provavelmente após 1945, a defasagem principal diz respeito ao nível de agregação de valor por empregado, tornando inviável a manutenção de níveis salariais relativamente superiores no contexto nacional, ainda que se tenha preservado a participação dos empregados no valor adicionado.

Recebido para publicação em 20 de agosto de 1999.

Ronaldo Herrlein Jr. (herrlein@ zaz.com.br) é economista da Fundação de Economia e Estatística (FEE).

\section{REFERÊNCIAS BIBLIOGRÁFICAS}

ACCURSO, C., CANDAL, A. \& VERAS, A. 1965. Análise do insuficiente desenvolvimento econômico do Rio Grande do Sul. Boletim da Comissão de Desenvolvimento Econômico, Porto Alegre/Santa Cruz, n. 16.

ALBUQUERQUE, E. S. 1998. O "Estado-região" Rio Grande do Sul : uma análise do regionalismo "oficial" (e do não-oficial) gaúcho. Boletim Gaúcho de Geografia, Porto Alegre, n. 23.

ALMEIDA, P. F. C. 1993. O processo de expansão da indústria do Rio Grande do sul entre
1930 e 1955. Dissertação (Mestrado em Economia). Campinas. 280 p. Instituto de Economia, UNICAMP. mimeo.

1996. A gestação das condições materiais da implantação da indústria gaúcha. In : TARGA, L. R. P. (org.). Gaúchos \& paulistas : dez escritos de história regional comparada. Porto Alegre : FEE.

BARAT, J. 1969. O investimento em transporte como fator de desenvolvimento regional : uma análise da expansão rodoviária no Brasil. $R e$ - 
vista Brasileira de Economia, Rio de Janeiro, v. 23 , n. 3 , p. $25-52$.

BRUM TORRES, J. C. 1983. A economia agrícola do Rio Grande do Sul e a Grande Depressão : 1920-39. Ensaios FEE, Porto Alegre, v. 2, n. 3, p. 67-108.

CANO, W. 1985. Desequilíbrios regionais e concentração industrial no Brasil : 1930-1970. São Paulo : Global.

CARDOSO DE MELLO, J. M. 1982. O capitalismo tardio : contribuição à revisão crítica da formação e do desenvolvimento da economia brasileira. São Paulo : Brasiliense.

CARDOSO, F. H. 1977. Capitalismo e escravidão no Brasil meridional. Rio de Janeiro : Paz e Terra.

CASTRO, A. B. 1971. A industrialização descentralizada no Brasil. In : Sete ensaios de economia brasileira. Rio de Janeiro : Forense.

CENSO INDUSTRIAL BRASIL. s/d. Série nacional. V. III, Tomo 1. Rio de Janeiro : IBGE.

CENSO INDUSTRIAL RIO GRANDE DO SUL. s/d. Série regional. V. XXVIII, Tomo 2. Rio de Janeiro : IBGE.

CENSO INDUSTRIAL SÃO PAULO. s/d. Série regional. V. XXV, Tomo 3. Rio de Janeiro : IBGE.

FEE (Fundação de Economia e Estatística) 1976. Análise da indústria de transformação no Rio Grande do Sul. 25 anos de economia gaúcha. V. 4. Porto Alegre : Fundação de Economia e Estatística.

. 1977. Aspectos demográficos e suas relações com o desenvolvimento econômico do Estado. 25 anos de economia gaúcha. V. 2. Porto Alegre : FEE.

1978. A agricultura do Rio Grande do Sul. 25 anos de economia gaúcha. V.3. Porto Alegre : FEE.

1981. De Província de São Pedro a Estado do Rio Grande do Sul : censos do RS, 18031950. Porto Alegre : FEE.

FONSECA, P. 1985. A transição capitalista no Rio Grande do Sul : a economia gaúcha na Primeira República. Estudos Econômicos, São Paulo, v. 15, n. 2, p. 263-289, mai.-ago.
FURTADO, C. 1982. Formação econômica do Brasil. São Paulo : Nacional.

HERRLEIN JR., R. \& DIAS, A. 1993. Trabalho e indústria na Primeira República : um ensaio de análise comparativa entre as sociedades do Rio Grande do Sul e de São Paulo. Ensaios FEE, Porto Alegre, v. 1, n. 14, p. 255-298.

LAGEMANN, E. 1980. Imigração e industrialização. In : DACANAL, J. H. \& GONZAGA, S. $R S$ : imigração e colonização. Porto Alegre : Mercado Aberto.

LIPIETZ, A. 1988. Miragens e milagres : problemas da industrialização no Terceiro Mundo. São Paulo : Nobel.

MEDEIROS, L. 1975. Formação da sociedade rio-grandense. Porto Alegre : URGS.

PESAVENTO, S. J. 1980. $R S:$ a economia \& o poder nos anos 30. Porto Alegre : Mercado Aberto.

1985. História da indústria sul-riograndense. Guaíba: Riocell.

.1988. A burguesia gaúcha : dominação do capital e disciplina do trabalho, RS, 1889-1930. Porto Alegre : Mercado Aberto.

.1989. A emergência dos subalternos : trabalho livre e ordem burguesa. Porto Alegre : UFRGS/FAPERGS.

PETERSEN, S. R. F. \& LUCAS, M. E. 1992. Antologia do movimento operário gaúcho. Porto Alegre : Editora da Universidade/Tchê.

RECENSEAMENTO DO BRASIL. 1940. Série regional. Parte XVII : São Paulo; Tomo 3, Parte XX : Rio Grande do Sul; Tomo 2; série nacional, V. III : censo industrial. Rio de Janeiro : IBGE.

RECENSEAMENTO DO BRAZIL. 1927. Indústria : 1920. Rio de Janeiro : s/n.

RECENSEAMENTO DO BRAZIL. 1928. Salários : 1920. Rio de Janeiro : s/n.

REICHEL, H. J. 1979. A industrialização no Rio Grande do Sul na República Velha. In : DACANAL, J. H. \& GONZAGA, S. $R S$ : economia e política. Porto Alegre : Mercado Aberto.

RIBEIRO, D. 1995. O povo brasileiro : a formação e o sentido do Brasil. São Paulo : Compa- 
nhia das Letras.

SILVA, S. 1986. Expansão cafeeira e origens da indústria no Brasil. São Paulo : Alfa-Ômega.

SINGER, P. 1977. Porto Alegre. In : . Desenvolvimento econômico e evolução urbana. Rio de Janeiro : Companhia Editora Nacional.

1984. Interpretação do Brasil : uma experiência história de desenvolvimento. In : FAUSTO, B. (org.). O Brasil republicano, III. Economia e cultura (1930-1964). São Paulo : Difel.

SOUZA, P. R. 1973. Un modelo primário exportador regional: el caso de Rio Grande do Sul, Brasil. Trabajo de seminario para optar al grado de Magister en Ciencias Económicas. Santiago. 124p. Faculdad de Economía y Política/ Universidad de Chile.

TARGA, L. R. P. 1982. Ensaio sobre a totalidade econômica. Porto Alegre : FEE.

1984. A economia do Rio Grande do Sul não é parte da economia nacional. Ensaios FEE, Porto Alegre, v. 2, n. 4, p. 161-164.

1988. O processo de integração do mercado interno brasileiro : eliminação das particularidades econômicas e sociais do Rio Grande do Sul. Ensaios FEE, Porto Alegre, v. 2, n. 9, p. 147-158.

1989. Comentário sobre os paradigmas da economia gaúcha. Ensaios FEE, Porto Alegre, v. 2, n. 10, p. 351-354.
1991. Comentário sobre a utilização do método comparativo em análise regional. Ensaios FEE, Porto Alegre, v. 1, n. 12, p. 265271.

(org.). 1996a. Gaúchos \& paulistas : dez escritos de história regional comparada. Porto Alegre : FEE.

. 1996b. O Rio Grande do Sul : fronteira entre duas formações históricas. In : (org.). Gaúchos \& paulistas : dez escritos de história regional comparada. Porto Alegre : FEE.

1996c. As diferenças entre o escravismo gaúcho e o das plantations do Brasil. In : (org.). Gaúchos \& paulistas : dez escritos de história regional comparada. Porto Alegre : FEE.

(org.). 1998. Breve inventário de temas do Sul. Porto Alegre/Lajeado : UFRGS/FEE/ UNIVATES.

TARGA, L. R. P., RIBEIRO, P. S. \& HERRLEIN JR., R. 1998. O Rio Grande do Sul e o mercado nacional. In : TARGA, L. R. P. (org.). Breve inventário de temas do Sul. Porto Alegre/Lajeado : UFRGS/FEE/ UNIVATES.

TAVARES, M. C. 1998. Acumulação de capital e industrialização no Brasil. Campinas : UNICAMP.

TEJO, L. 1939. A indústria rio-grandense em função da economia nacional. Porto Alegre : Globo. 